\title{
THE DEVELOPMENT OF THE ROLLING TEXTURE OF IRON DETERMINED BY NEUTRON-DIFFRACTION
}

\author{
D. SCHLÄFER and H. J. BUNGE \\ Zentralinstitut für Festkörperphysik und Werkstofforschung Dresden \\ der Akademie der Wissenschaften der DDR, GDR
}

(Received May 2, 1972; revised June 28, 1972)

\begin{abstract}
The development of the rolling texture of a low carbon steel was investigated by neutron diffraction calculating three-dimensional orientation distribution functions. The textures consist of two limited fibre axis components $A$ and $B$ centered about (111) [121] $+5^{\circ}$ and (001) [110] respectively with an angle of rotation of about $70^{\circ}$. For rolling degrees larger than $50 \%$ the intensity of the fibre axis component $A$ is being modulated so as to favour the orientation (112) [110]. The texture may be considered as inverse to the low concentration brass texture in the sense of interchanging rolling and normal directions. It may be understood in terms of $\{110\}\langle 111\rangle$-glide and $\{112\}\langle 111\rangle$ -twinning.
\end{abstract}

\section{INTRODUCTION}

The rolling textures of bcc metals, especially that of iron, have been studied in several investigations. Although the results were more uniform than in the case of fcc metals, the interpretation of the textures in terms of ideal orientations proved even more difficult than in the fcc case. Wever and Bötticher ${ }^{1}$ interpreted their pole figures by three orientations (112) $[110]+(111)[\overline{2} 11]+(001)[110]$. This description, in some respects, is inverse to that one used for fcc metals. The first two orientations correspond to the copper type ideal orientations and the third one is analogous to the twin-orientation (110) [001] occurring in the brass type if normal and rolling directions were interchanged.

A description of textures which takes into account at least part of the spread about the ideal orientations is the limited fibre axis model proposed by Grewen and Wassermann. ${ }^{2}$ It was applied to bcc metals by Haessner and Weik. ${ }^{3}$

The complete (three-dimensional) orientation distribution function for a $70 \%$ cold-rolled iron sheet was calculated by Bunge ${ }^{4}$ using pole figures measured by Takechi et al. ${ }^{5}$ The results corroborated a certain analogy with the fcc type texture in as far as a continuous tube of preferred orientations was found stretching from (112) [110] to approximately (111) [2111]. At the same time, however, also the differences were revealed more clearly. In the bcc case the orientation tube exhibited a strongly elongated cross-section as compared with the nearly circular one in the fcc case.
Similar results were obtained recently by Heckler and Granzow ${ }^{6}$ who used the three-dimensional analysis too in order to study the texture development in low-carbon steels. These authors, however, used the ideal orientation (111) [110] instead of (111) [ $\overline{2} 11]$ mentioned above. Although this seems to be a large difference, really it only requires a shift within an area of nearly constant orientation density-thus showing anew the inadequacy of an ideal orientation description.

Three-dimensional orientation distribution functions calculated from pole figures by means of a series development, of course, are subject to truncation errors, as a consequence of which the maximum point of the orientation density may easily be shifted within a region of nearly constant density, hence giving rise to different interpretations of the texture. In order to reduce these uncertainties a higher "resolving power" is required. This can be achieved by increasing the number of terms used in the series development, by increasing the number of pole figures, and by reducing their possible errors by using neutron diffraction instead of X-ray diffraction, for example. Thus the aim of the present investigation was to study the texture development in iron during rolling in further detail.

\section{EXPERIMENTAL}

The material used was a low-carbon steel of the following composition: $0.06 \% \mathrm{C}, 0.3 \% \mathrm{Mn}$, 
$0.014 \% \mathrm{P}, 0.028 \% \mathrm{~S}, \mathbf{9 9 . 6} \% \mathrm{Fe}$. It was received in the hot rolled state, in which it proved to be nearly free of preferred orientation. Subsequent cold rolling was carried out by VEB Bandstahlkombinat within the usual production line in five steps up to $86 \%$ reduction. The sheets were $400 \mathrm{~mm}$ in width and the neutron diffraction samples were taken from the central part. An $80 \mathrm{~mm}$ wide strip of the $86 \%$ reduced sheet was given a further reduction to a total of $95 \%$ using a laboratory mill. This strip showed a certain amount of texture inhomogeneity in the transverse direction which gave rise to a somewhat larger error coefficient of the texture measurement.

The texture determinations were carried out by neutron diffraction using a texture goniometer described by Tobisch et al., ${ }^{7}$ which was mounted on the neutron diffractometer described by Kleinstück. ${ }^{8}$ The procedure of measurement closely followed that one used by Kleinstück and Tobisch. ${ }^{9}$ Samples of $70 \times 70 \mathrm{~mm}$ were taken from the middle part of the cold rolled sheets. For the higher rolling degrees several of them were stacked one upon the other such as to form a sample of about $1 \mathrm{~mm}$ thickness. The pole figures were scanned along concentric circles about the normal direction in steps of $6^{\circ} \times 6^{\circ}$. The intensity figures of the reflected neutron beam were automatically punched into paper tape. By means of a computer programme they were corrected for background scattering, absorption and geometrical factors and were normalized to multiples of the random distribution. Four pole figures were taken for each specimen, namely (110), (200), (211) and (310). They are the ones having the lowest glancing angles. The more symmetric (222) pole figure could not be measured without changing to a shorter wavelength because of the limited range of glancing angles available to the diffractometer. On the other hand the "resolving power" as it was defined in reference ${ }^{11}$, i.e. the number of coefficients that are uniquely determinable, does not depend on the type of the pole figures employed but only on their number. From this point of view any pole figure may be used as well. There may be a difference, however, as far as the experimental errors are concerned; we will discuss this point later. The series were extended to the degree $l=22$. A table of the coefficients $C_{l}^{\mu \nu}$ of the three-dimensional distribution functions is given in the Appendix. The pole figures and the resulting three-dimensional functions were automatically plotted using a computer operated plotter. ${ }^{12}$
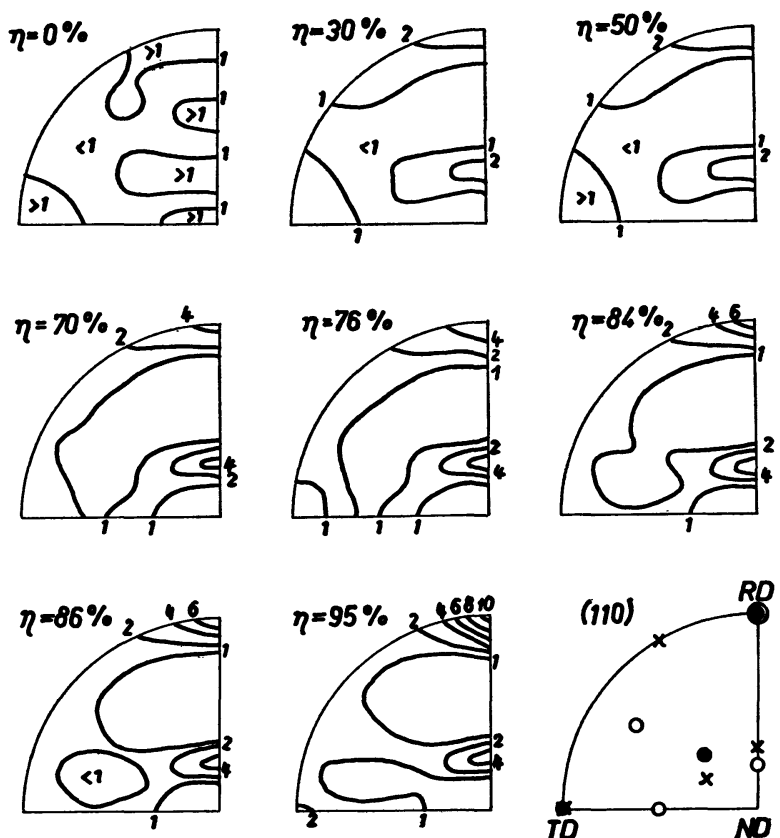

$\times(111)[11 \overline{1}] \quad \circ(121)[10 \overline{1}]$

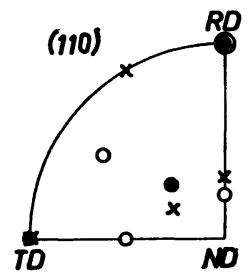

(a)
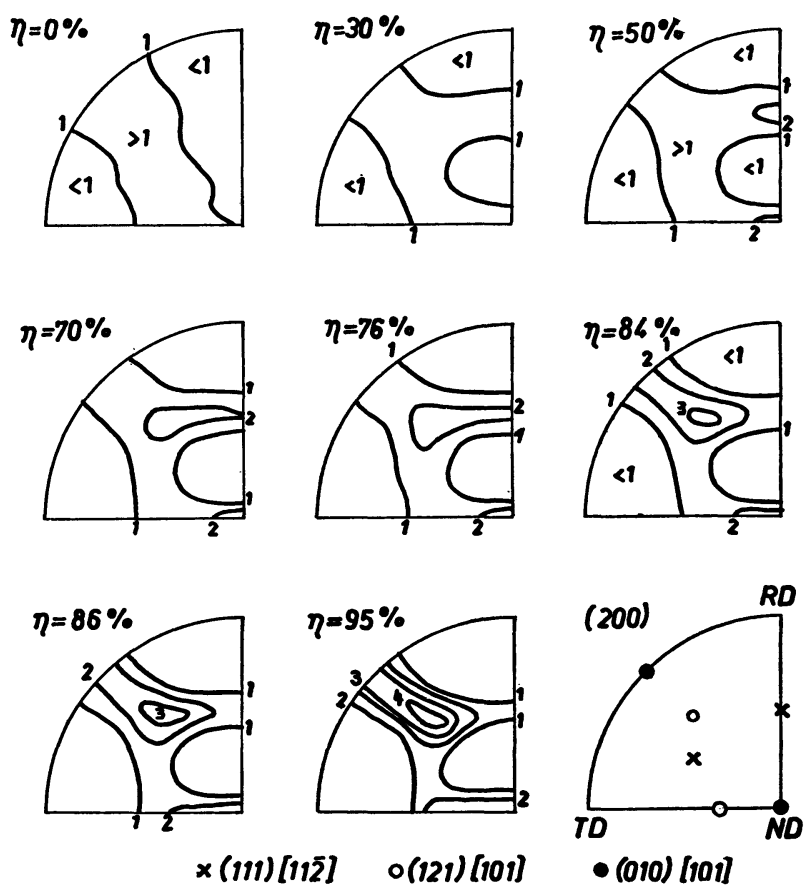

(b) 

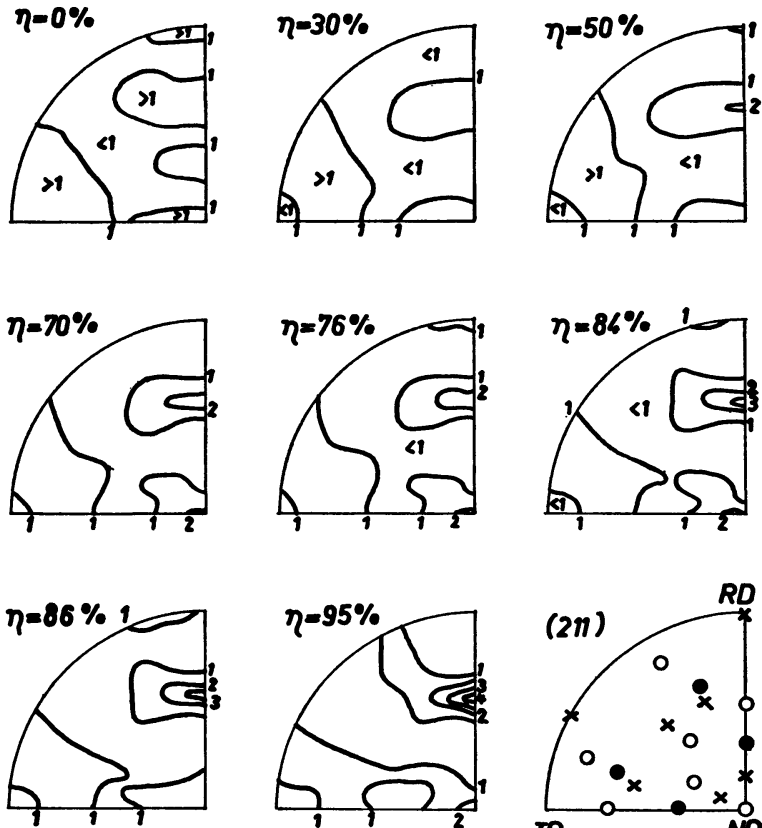

$\times(111)[112]$

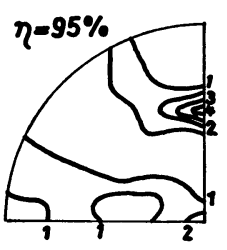

o(121) [10i]

(c)
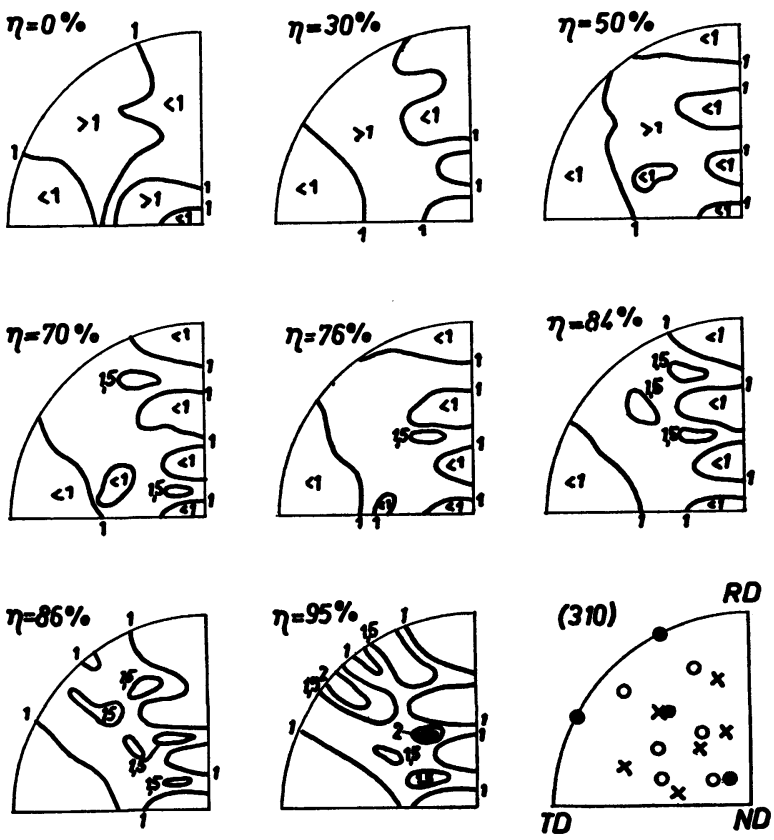

$x(111)[115]$

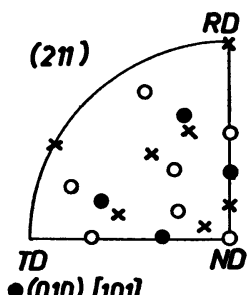

$\bullet(010)$ [101]

\section{$(000)[100]$} Fig. 1 for different degrees of cold reduction in a logarithmic scale $(-\log (100-\eta))$.

FIGURE 1 Normalized pole figures for different degrees of cold reduction.

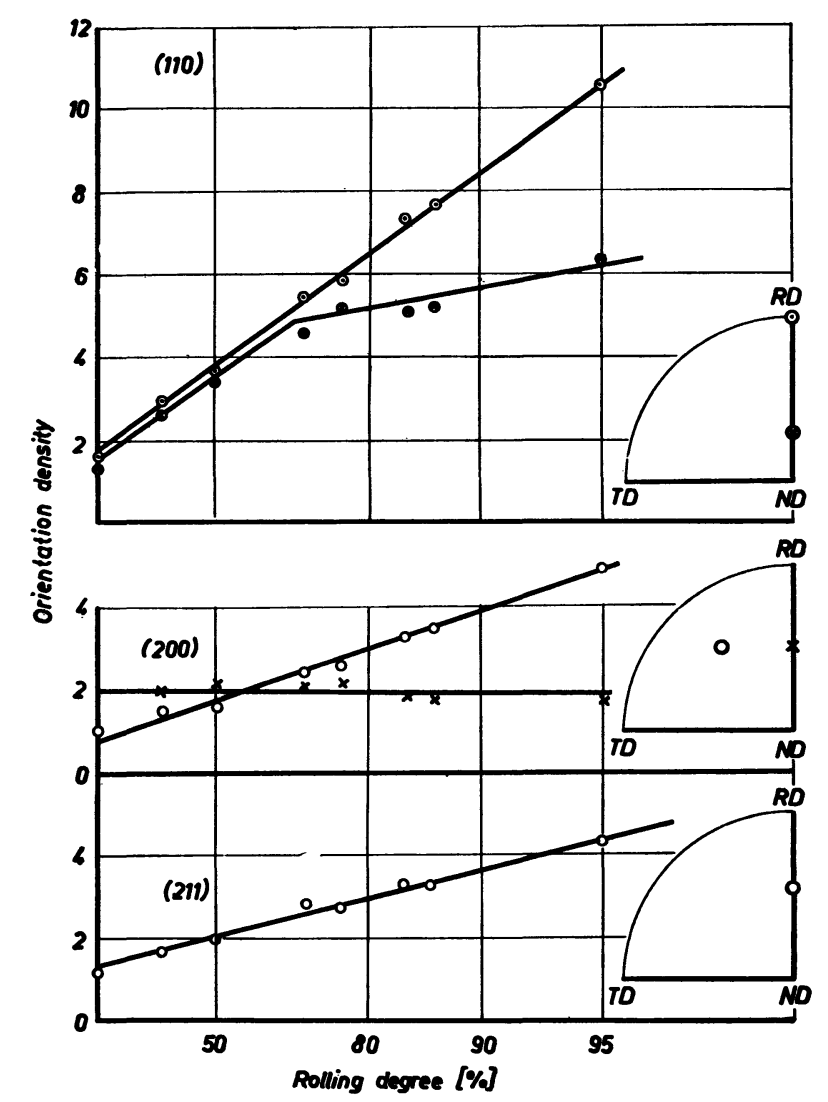

FIGURE 2 Pole densities taken at points indicated in

\section{RESULTS}

The results of the pole figure measurements are shown in Figures 1a-d. The increase of the pole density at certain points of the pole figures is shown in Figure 2. A logarithmic scale was used for the rolling degree $(-\log (100-\eta))$ so that equal reductions in area will be represented by equal intervals of the scale. It is to be seen that the pole density at different points develops in a different way. At certain points of preferred orientation it increases linearly, whereas at others there is a point of inflection. (At other points, corresponding to nonpreferred orientations, the density is reduced or at least remains constant.) Figure 2 shows that the texture does not develop continuously throughout the whole range of reduction. At least two subranges can be distinguished corresponding to deformations smaller and larger than about $60 \%$ reduction. However, this will be illustrated more clearly in the three-dimensional functions.

(d) 
160
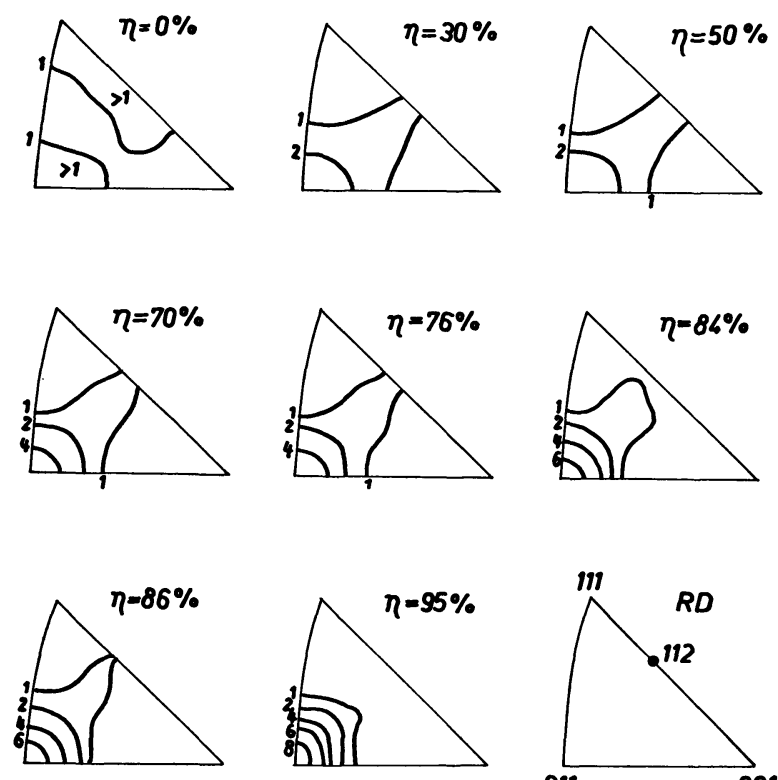

(a)
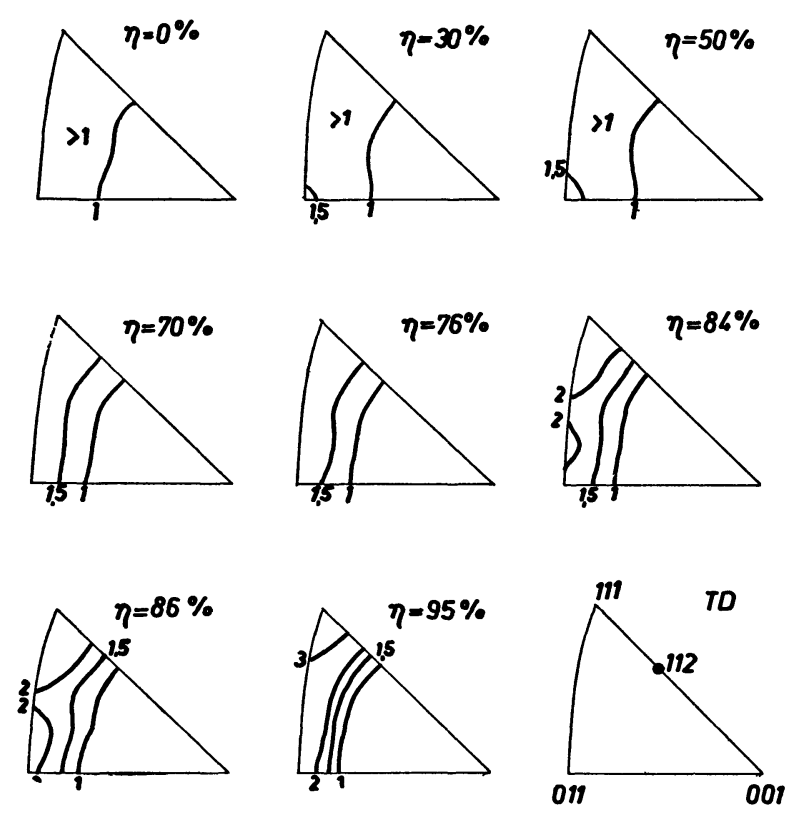

(b)
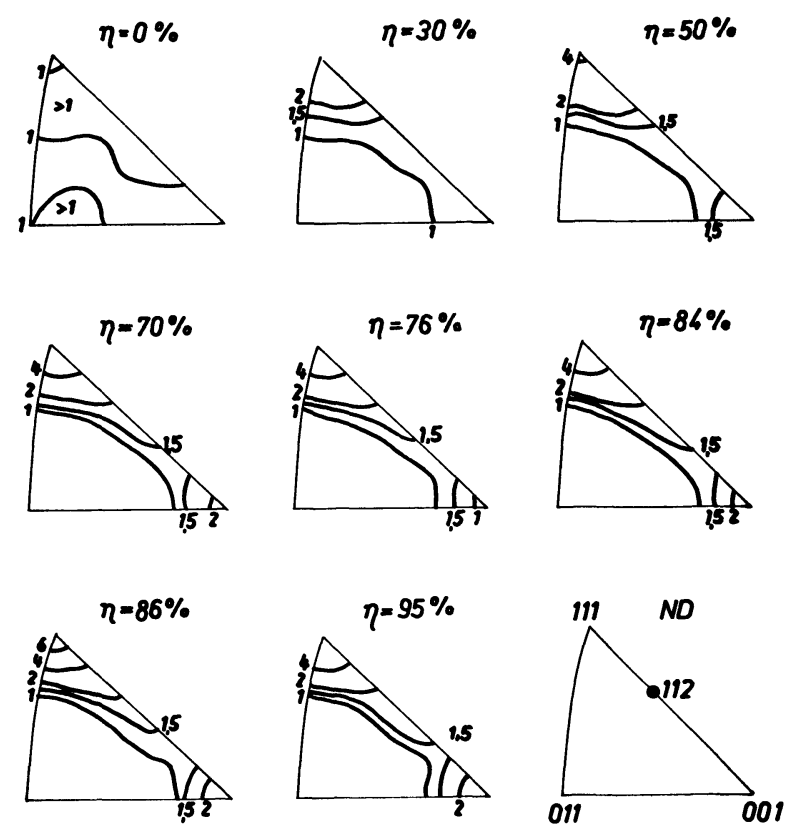

(c)

FIGURE 3 Inverse pole figures for different degrees of cold reduction (in multiples of the random distribution).

Inverse pole figures calculated from the conventonal pole figures are shown in Figs. 3a-c. Like the conventional ones, they are only two-dimensional projections of the complete three-dimensional orientation distribution function. Hence they cannot, by themselves, resolve the orientation distribution much clearer than the pole figures can. However, the inverse pole figure of a certain specimen direction is closely related to the mean values of physical properties measured along this direction. Hence they may be useful even if three-dimensional functions are available. Figure 4 shows the developmont of the orientation densities in inverse pole figures (axis densities) taken from Figure 3 for certain low index directions. As in the case of the conventional pole figures the densities at certain orientations increase linearly, whereas at others they reach a saturation value.

The three-dimensional orientation distribution functions calculated in $5^{\circ}$ steps are shown in Figures $5 \mathrm{a}-\mathrm{h}$. They are represented in constant $\phi_{1}$ sections (ref. ${ }^{11}$ ). Two texture components are to be distinguished, the one labeled A corresponds to a continuous tube of preferred orientations running through the whole orientation space, whereas the other one labeled $B$ is centered about 
the ideal orientation (001) [1110]. There is, however, a strong spread between the two components $A$ and B, perpendicular to the axis of the tube component A. Thus at certain points the tube has an extremely elongated cross-section resembling more nearly a two-dimensional plate than a one-dimensional tube. Hence it is difficult and somewhat arbitrary

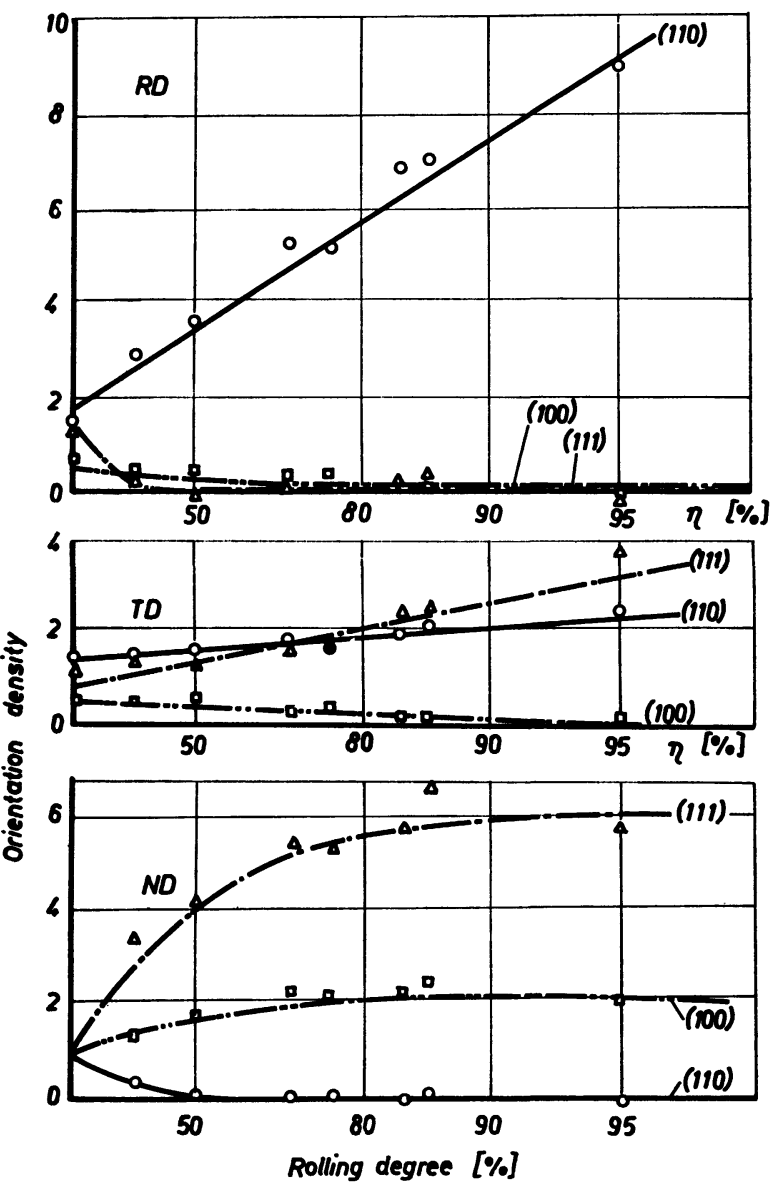

FIGURE 4 Axis densities taken at the three low-index points from Fig. 13 as a function of the degree of cold reduction.

to locate the points of maximum orientation density within the range of spread. In Figure 6 the points of maximum density are shown in stereographic projection for the rolling and normal directions. (For the relationship between the Euler angles at the stereographic projection ref. ${ }^{11}$.) One can see that the tube of preferred orientations A runs from (112) [110] to an orientation approximately $5^{\circ}$ apart from (111) [121], points a and b.
The branches $b-c$ and $c-d$ (the latter being not fully shown in Figure 6) are equivalent to $a-b$ because of the crystal symmetry. The component B starts at the orientation (001) [1110], point $e$, and runs

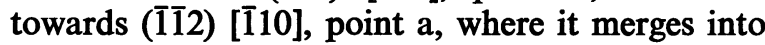
component A. Hence the texture may be described as consisting of two limited fibre axis components. The axis of component $A$ is the [101] direction which is situated $30^{\circ}$ from the normal direction towards the rolling direction, and component $B$ has its [110] axis in the rolling direction. The rotation angle of both these fibre textures is $70^{\circ}\left(35^{\circ}\right.$ to either side), Figure 6.

The orientation density along the skeleton line of component $A$ is shown in Figure 7 . It is seen that at lower degrees of deformation the density is nearly constant along the whole tube, whereas at higher degrees a strong maximum is being developed at the orientation (1112) [110], point c.

Figure 8 shows the density along the spread range of component $B$, points e to $a$. It is clearly seen how component B merges into $A$. The somewhat wavy shape of these curves must be regarded as an artificial effect due to the truncational error.

In Figure 9 the orientation density at the three main points of the texture, namely (1112) [1110], (1111) $[\overline{1} 21]+5^{\circ}$, and (001) [1110] are shown as a function of the degree of deformation. The first one of these orientations increases steadily throughout the whole range of deformations investigated. The second one increases up to about $60 \%$, and remains nearly constant afterwards. The third orientation also increases throughout the whole range of deformation; and it seems doing so even at a slightly increased rate for deformations above about $60 \%$. In Figure 10 the mean absolute values of the coefficients $C_{t}^{\mu v}$ are compared with the corresponding mean absolute errors (ref. ${ }^{11}$ ) for the specimens deformed $0 \%$ and $86 \%$ respectively. It is to be seen that for the $0 \%$ specimen the coefficients have decreased to the level of experimental error already at $l=10$. This series could have been terminated at this degree without increasing the uncertainty by an additional truncation error. On the other hand, the coefficients of the $86 \%$ texture are slightly above the level of errors even at $l=22$. In this case extending the series beyond 22 would have slightly improved the results. It would, however, also have increased considerably the computer time and space needed. Thus a series development up to $l=22$ was chosen as a compromise between the highest possible accuracy and the necessary effort. For more detailed investigations 

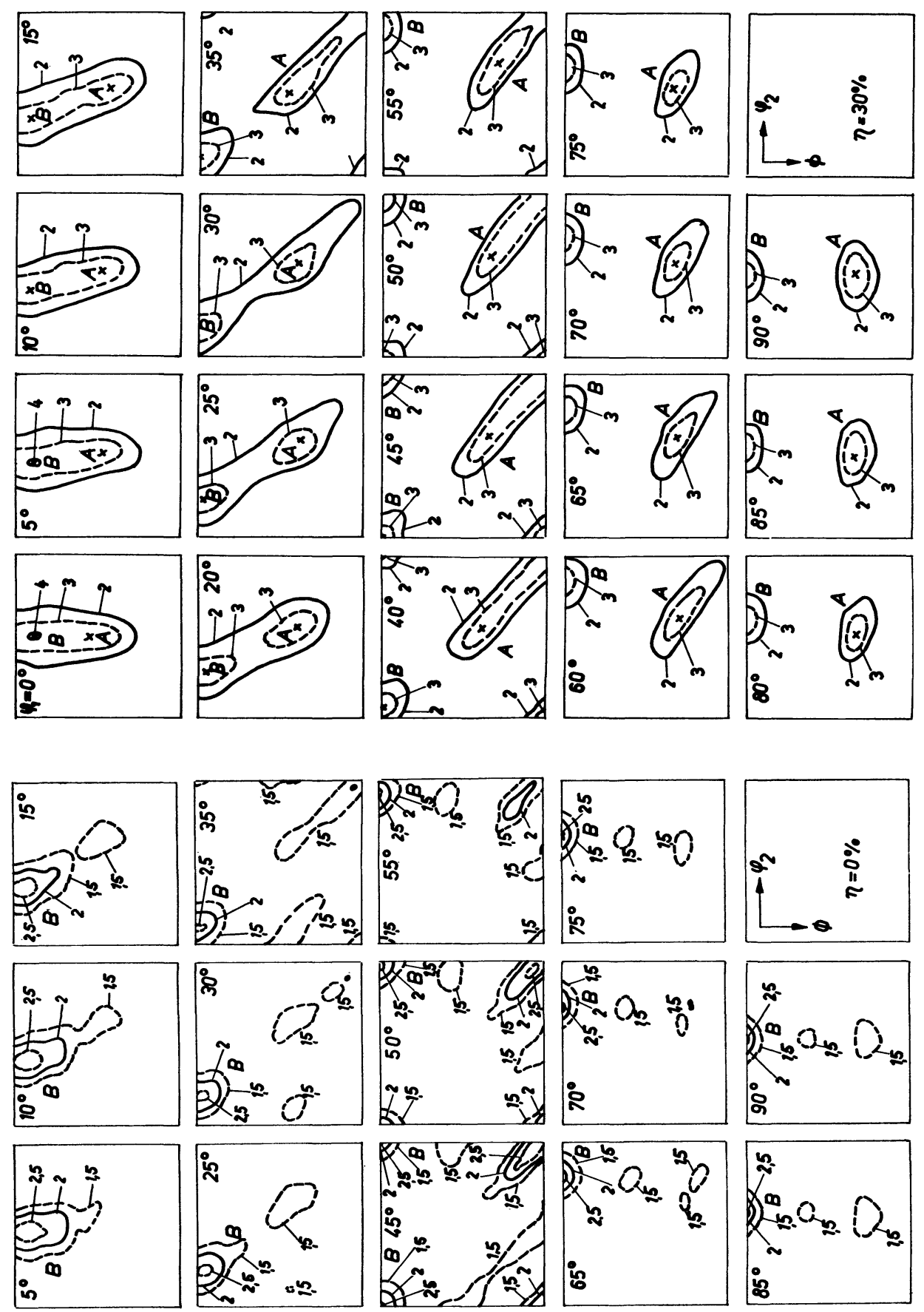

$\tilde{x}_{\infty}^{\infty} a_{2} \hat{O}_{2}$
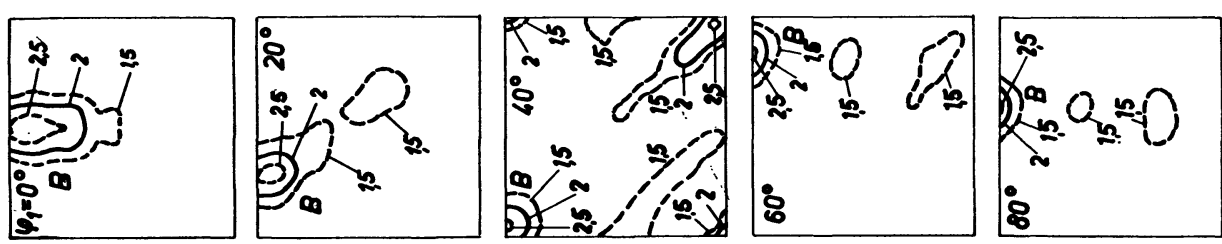

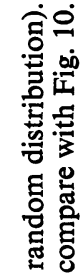

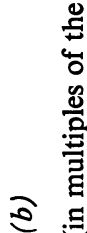

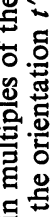

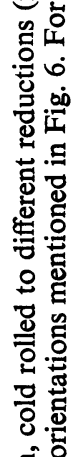

ธี่ํำ

哭

ปั)

둥

s.

.

(อ)

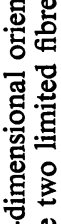

\&்

空号

S효

을

幽密

号志 

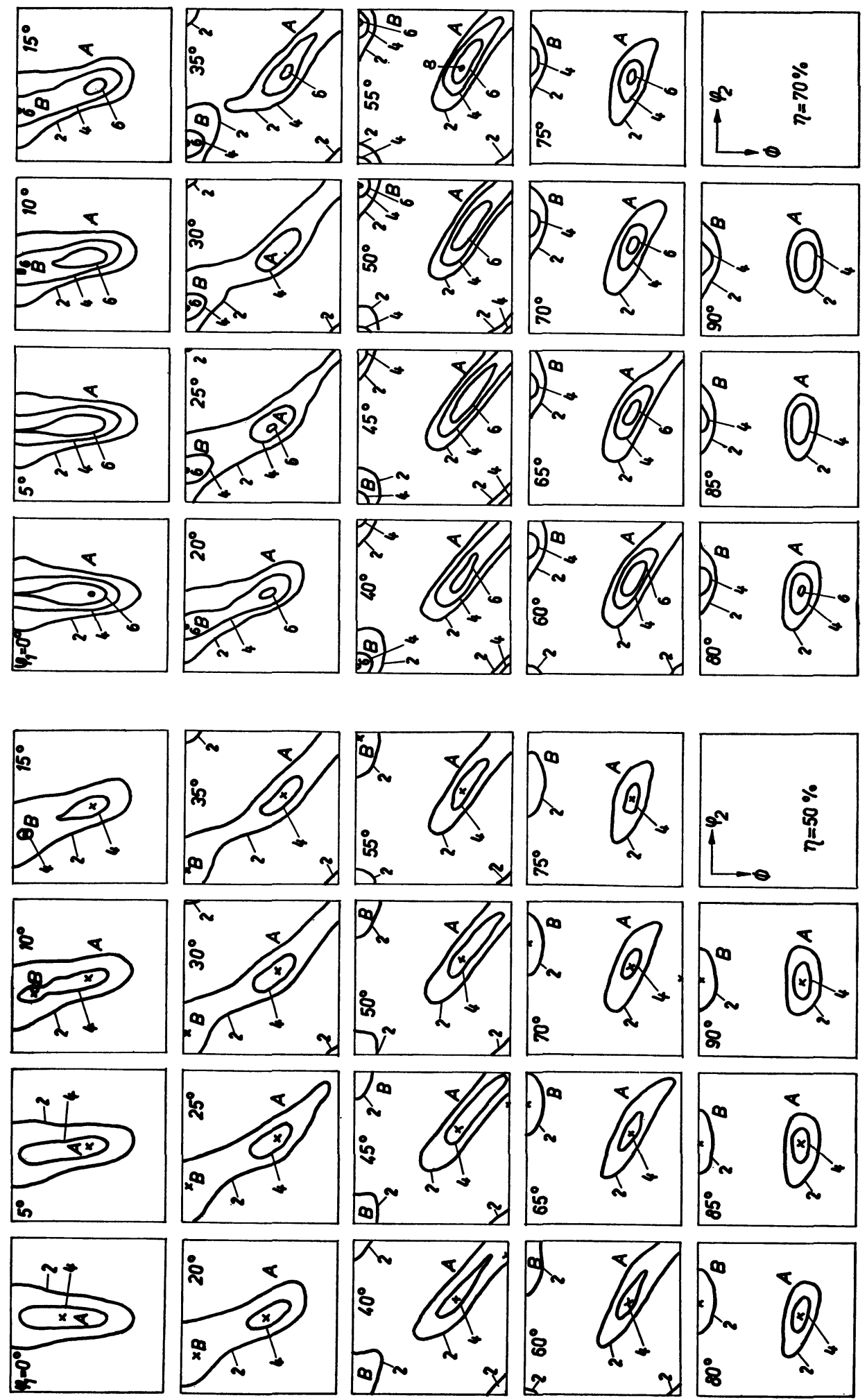

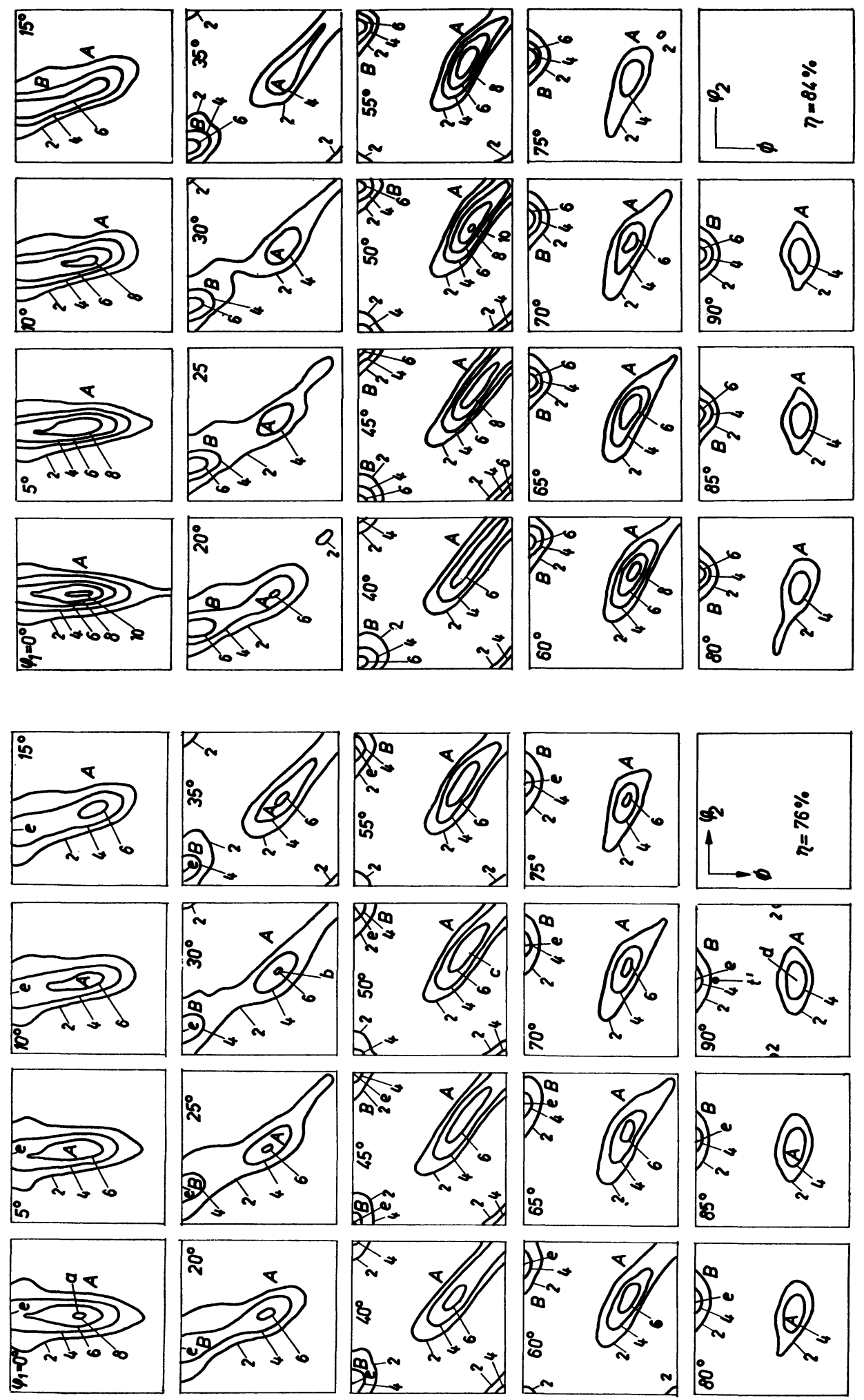

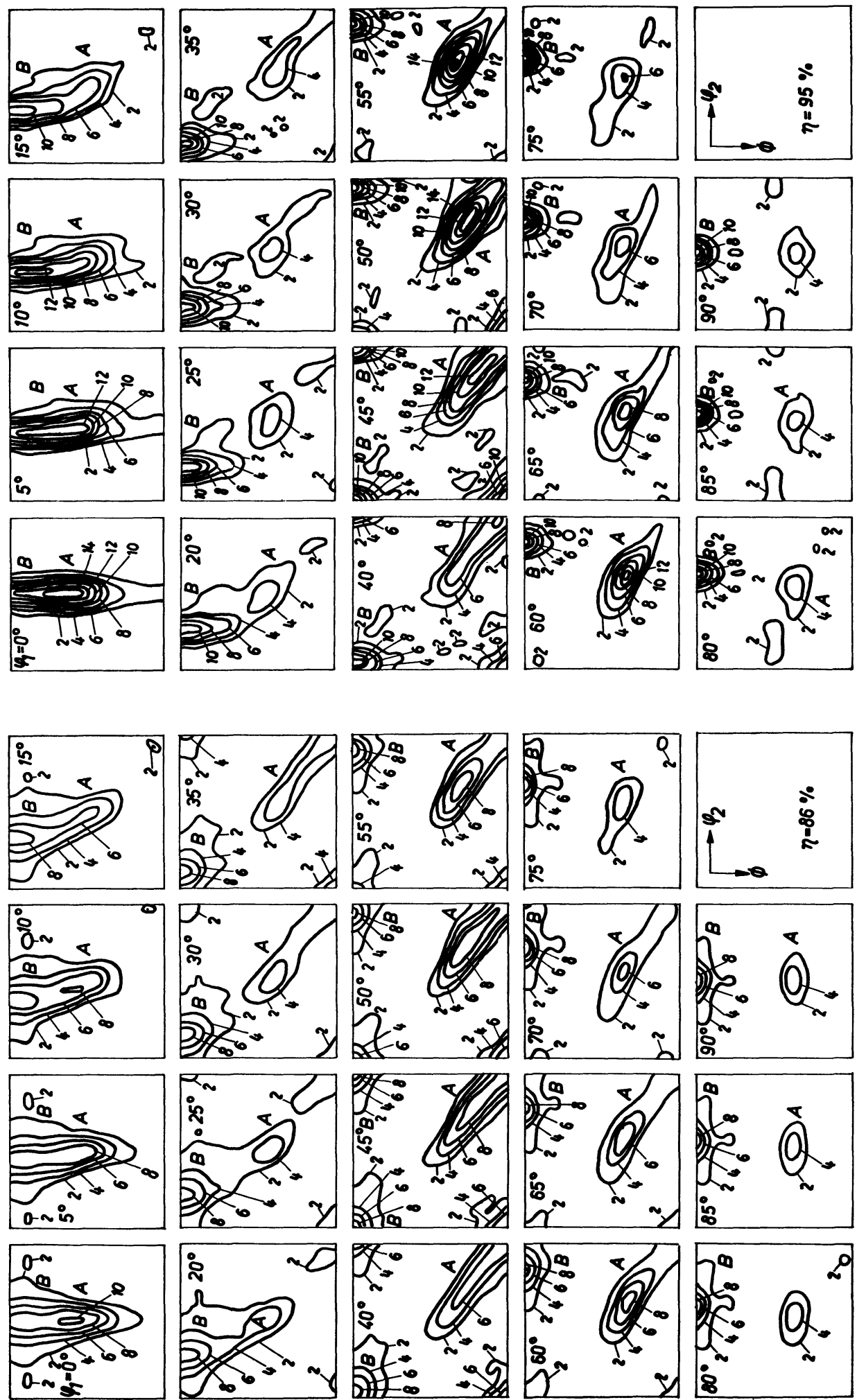


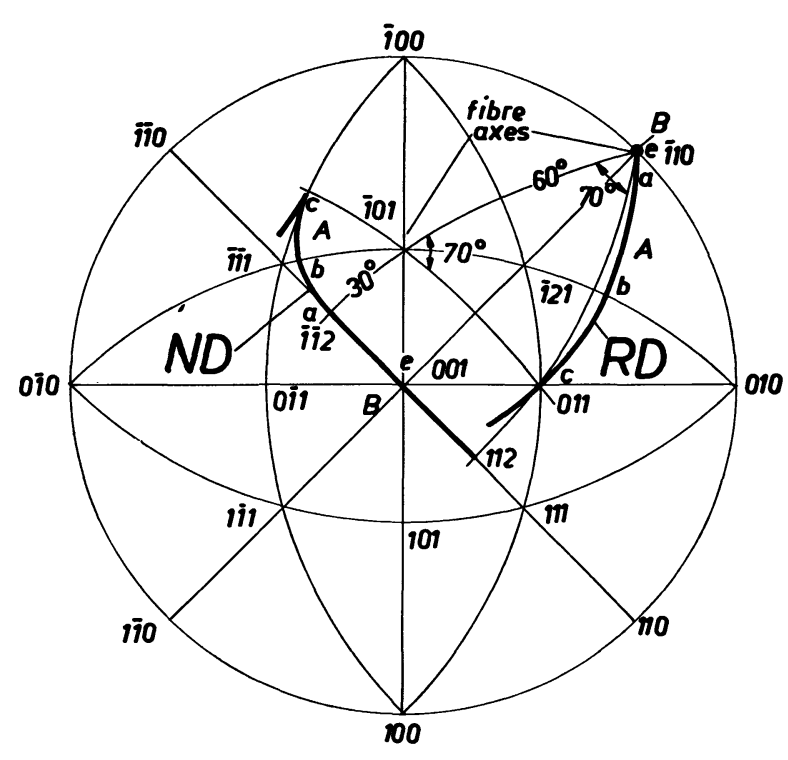

FIGURE 6 The "skeleton lines" of the two limited fibre components axes in stereographic projections for the rolling and normal directions.

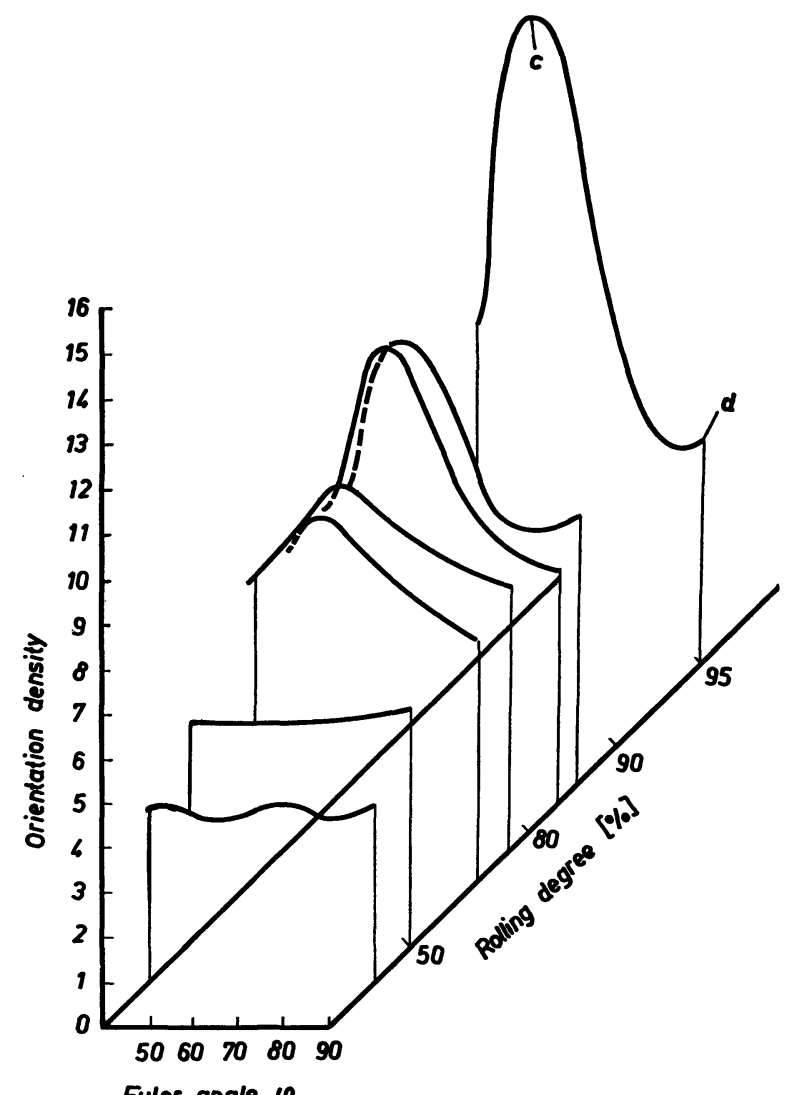

FIGURE 7 The orientation density along the skeleton line of the component $A$.

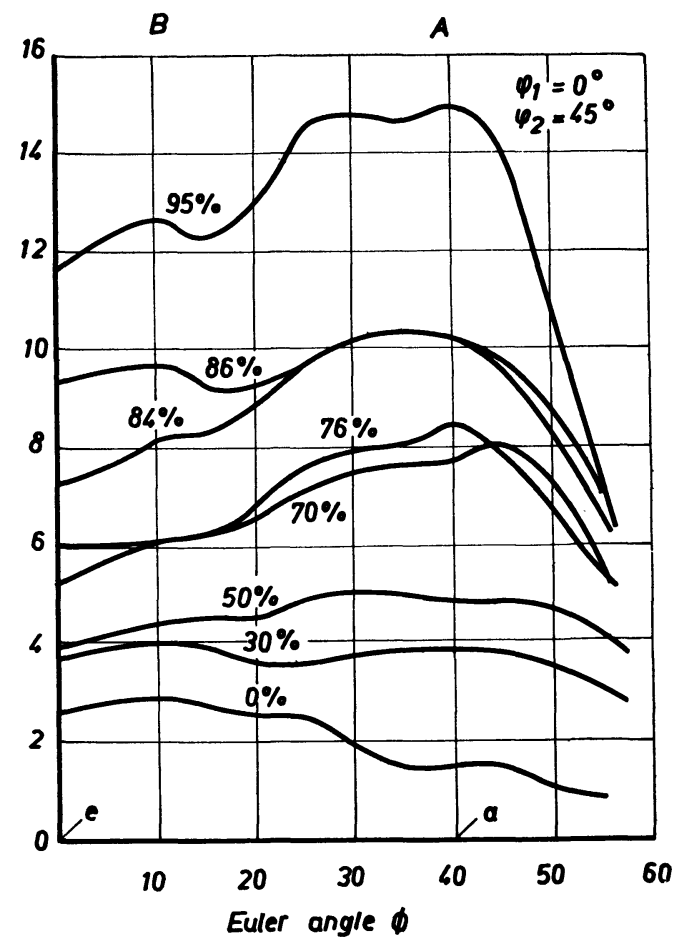

FIGURE 8 The orientation density along the skeleton line of component $B$ merging into $A$.

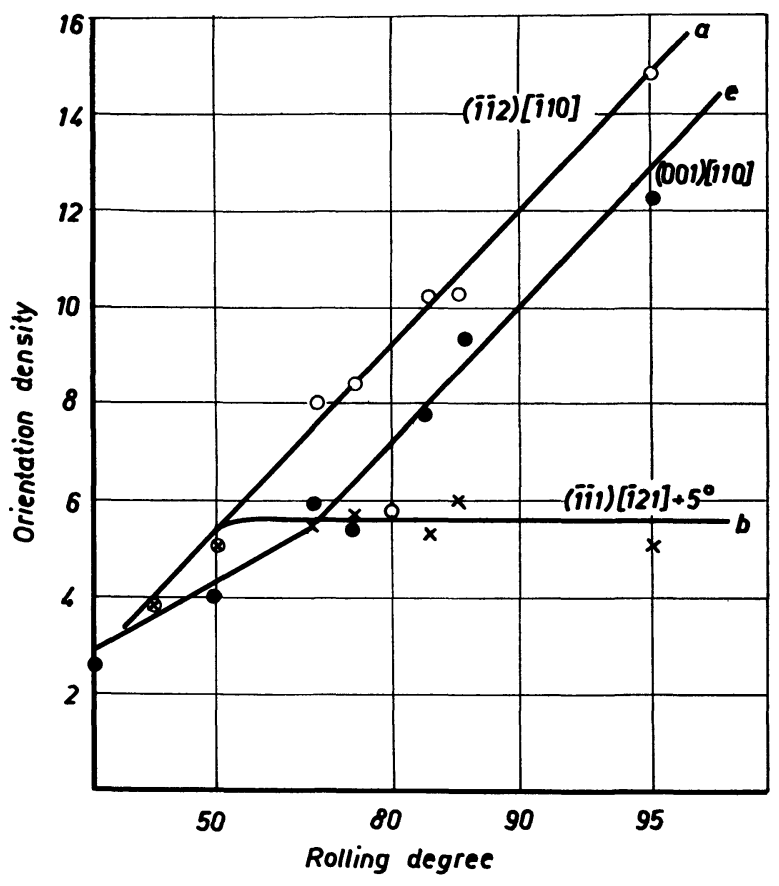

FIGURE 9 The orientation density at the three main orientations of the texture as a function of the rolling degree. 
in the future, however, especially if sharp textures are concerned and the experimental errors are further reduced, extending the series to higher degrees certainly will be necessary.

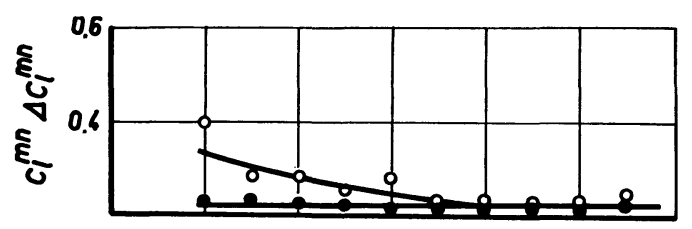

a)

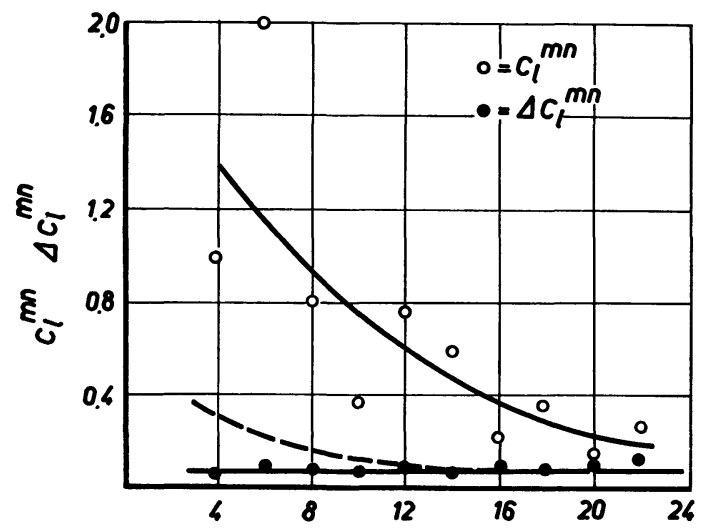

FIGURE 10 The mean absolute values of the coefficients $C_{l}^{m n}$ and their errors $\Delta C_{l}{ }^{m n}$ for the $0 \%(a)$, and $86 \%(b)$, cold rolled material. The dashed curve corresponds to the errors of a comparable texture determined by X-ray methods. ${ }^{26}$

In Figure 10b, as a dashed line the error curve for a comparable texture determined by X-ray methods is shown (ref. ${ }^{26}$ ). This curve starts at about three times as high a value at low values of $l$, indicating a systematic error twice as large as the statistical error which is assumed to be responsible for the $l$-independent part of the error curve. The error curves of the present neutron diffraction measurements proved nearly independent of $l$. Thus it may be assumed that the measurements were not essentially influenced by systematic errors such as, for example, improperly corrected absorption. In the preceding section it was mentioned that the experimental error could have been somewhat decreased by using the more symmetric (222) pole figure instead of (211) or (310) because of its lower multiplicity factor. Since, however, at least with the medium and high rolling degrees, the accuracy was limited by the truncation error and not by the experimental one, this would not have noticeably improved the results.

\section{CONCLUSIONS}

The rolling texture of the low-carbon steel investigated consists of two limited fibre axis components. The one labeled A runs from (1112) [1110] towards (ī11) $[\overline{1} 21]+5^{\circ}$. Its fibre axis is a [i101] direction, which is situated $30^{\circ}$ from the normal direction towards the rolling direction. The component labeled B runs from (001) [ī10] towards (1112) [1110]. Its [110]-fibre axis is parallel to the rolling direction. In both these components the angle of rotation is about $70^{\circ}$. The same model was already deduced from (110) pole figure by Haessner and Weik $^{3}$; however, the angle of rotation and other quantitative characteristics were not determined.

Component $A$ is the inverse to the tube of preferred orientations occurring in the copper type texture. By "inverse" it is meant that rolling-and normal directions are interchanged. A correspondence of this type between the rolling textures of bcc and fcc metals is to be expected if deformation takes place on an "inverse" glide system, i.e. glide planes and glide directions are interchanged in the same way. For fcc metals the theoretical endorientations were calculated ${ }^{13}$ on the basis of the Taylor model ${ }^{14}$ assuming $\{111\}\langle 110\rangle$ glide only. They agreed reasonably well with the experimentally determined rolling texture of copper. ${ }^{13,15}$ The inverse model can be applied to bcc metals if only $\{110\}\langle 111\rangle$-glide is assumed. The resulting ideal orientations agree reasonably well with component A. ${ }^{13}$ As a characteristic feature of this theory the exact position of the point $b$ may be considered to be $(\overline{1} \overline{1} \overline{8} 11)\left[\begin{array}{lll}\overline{4} & 11 & 4\end{array}\right]^{16}$ This is about $8^{\circ}$ apart from the low index orientation (1111) [1121]. The experimentally observed deviation, Figure 6, was about $5^{\circ}$. Furthermore, it was shown that the theoretical deviation moves towards smaller values, i.e. towards the experimental value of $5^{\circ}$, if a certain amount of relative broadening during rolling is taken into account. It must be borne in mind, however, that the resolving power of the experimental and mathematical method used here is about $5^{\circ}$ and that a spread about the central lines of texture components occurs with a half-maximum width of about $10^{\circ}$ to $15^{\circ}$. Thus deviations of $3^{\circ}$ between experimental and theoretical orientations are within the limit of error.

As a second theoretical texture component, the orientation (001) [110] was found which is the centre of the experimental component $\mathrm{B} .^{13}$ For the lower rolling degrees the orientation density is uniform over the whole length of component $A$, and it 
increases steadily with deformation and so does the density of component $\mathbf{B}$. Thus for the lower rolling degrees the texture behaves as is to be expected within the scope of the Taylor theory, taking into account only $\{110\}\langle 111\rangle$ glide.

As is seen in Figures 7 and 9, however, this behaviour changes at about 50 to $60 \%$ deformation. From there on the density at the orientation (1111) $[\overline{1} 21]+5^{\circ}$ stops increasing, whereas at $(\overline{1} 12)[\overline{1} 10]$ it continues to increase at the same rate as before. Now (112) [110] is the inverse to the brass-orientation (110) [1112] of the fcc metals. This may suggest that the other component (111) [1121] is being disassembled by the same mechanism as it is believed

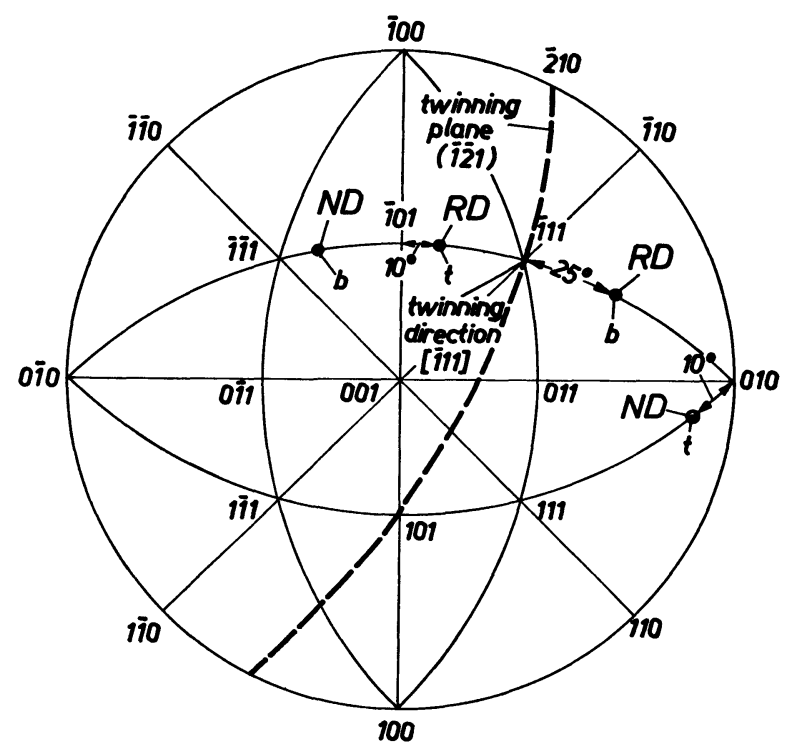

FIGURE 11 The orientation (111) [121] $+5^{\circ}$ and its twin orientation $t$ corresponding to the (121) [111]-twinning system.

to be in the brass-type texture, namely by a twinning mechanism. ${ }^{17}$ The most prominent twinning systems in bcc metals are the $\{112\}\langle 111\rangle$ systems, ${ }^{18}$ which are inverse to the corresponding twinning systems $\{111\}\langle 112\rangle$ in fcc metals. The special

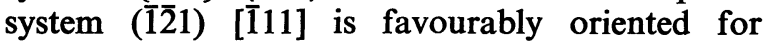
twinning in crystals in the (111) $[\overline{1} 21]+5^{\circ}$ orientation. The (1̄21)-twinning plane of this system is perpendicular to the plane ND-RD, and the [1111]twinning direction deviates by $25^{\circ}$ from the rolling direction towards the normal direction as is shown in Figure 11. Twinning of this kind transfers the orientation $b$ into the twin orientation $t$ which is only $10^{\circ}$ off the orientation (010) [101], the latter being a symmetrical equivalent to point $e$, the centre of component B. The symmetrical equivalent $t^{\prime}$ to $t$ is shown in Figure $5 \mathrm{e}$; it falls into the spread range of component B. From Figure 9 it may be concluded that this twinning mechanism starts to operate at about $50 \%$ deformation. Although the $b$ orientation is not destroyed completely it no longer increases as the (1112) [110] orientation does. The situation very much resembles that found in low concentration brasses. ${ }^{19}$ On the other hand, the orientation (001) [110] seems to increase at an enhanced rate. This can be understood if this orientation is being produced, from there on, by an additional mechanism namely twinning of the orientation $b$.

According to the above discussion, the rolling texture of iron can be understood in terms of $\{110\}\langle 111\rangle$-glide and $\{112\}\langle 111\rangle$-twinning, the latter occurring above $50 \%$ deformation. From this point on the flow stress must be assumed high enough to induce twinning, very much in analogy to the behaviour of brass as was shown by $\mathrm{Hu}$ and Goodman $^{20}$ by X-ray diffraction and recently by Leffers and Grum-Jensen ${ }^{21}$ by electron microscopy.

In fcc metals and alloys the well-known texture transition from the copper to the brass type is generally agreed to be a function of stacking fault parameter $\gamma / G . b^{22}$ where $\gamma$ is the stacking fault energy, $G$ the shear modulus and $b$ the Burgers vector (ref. ${ }^{23}$ ). According to English and Chin, ${ }^{24}$ the transition may be divided into a high and a low stacking fault energy regions. If the above mentioned analogy between fcc and bcc metals is accepted, then a texture transition might also be expected in bcc metals. Up to now, however, there seems to be no experimental evidence for such a transition. Haessner and Mayer-Rosa ${ }^{25}$ investigated different bcc metals, and stated that there are no significant differences in the rolling textures. As the present findings show the rolling texture of iron is to be compared with that of a low concentration brass whose texture is in the middle of the whole transition range between the copper and the brass types; and the differences in the stacking fault parameter among the bcc metals so far investigated may not have been sufficient to produce the pure end-textures of the transition range. Since all the previous investigations of different bcc metals have been conducted by determining their pole figures only, the calculation of three-dimensional distribution functions would be desirable to 
reveal more subtle differences in their textures, and consequently, to decide whether or not there is a texture transition similar to the fcc case.

\section{ACKNOWLEDGEMENT}

The authors want to express their gratitude to VEB Bandstahlkombinat for providing the required material, to Dr. D. Schleusener for the preparation of specimens as well as other useful cooperation, and to J. Tobisch for his assistance in the neutron diffraction measurements.

\section{REFERENCES}

1. F. Wever and H. Bötticher, Z. Metallk. 57, 472 (1966).

2. J. Grewen and G. Wassermann, Acta Met. 3, 354 (1955).

3. F. Haessner and H. Weik, Arch. Eisenhüttenw. 27, 153 (1965).

4. H. J. Bunge, Phys. stat. sol. 26, 167 (1968).

5. H. Takechi, H. Kato and S. Nagashima, Trans. Metall. Soc. AIME 242, 56 (1968).

6. A. J. Heckler and W. G. Granzow, Trans. Metall. Soc. AIME 1, 2089 (1970).

7. J. Tobisch, M. Betzl and P. Reichel, Exp. Techn. Phys. 17, 391 (1969).

8. K. Kleinstück, Kernenergie 4, 913 (1961).
9. K. Kleinstück and J. Tobisch, Kristall und Technik 3,455 (1968).

10. H. J. Bunge, Z. Metallk. 56, 872 (1965).

11. H. J. Bunge, Mathematische Methoden der Texturanalyse (Akademie-Verlag, Berlin, 1969).

12. H. J. Bunge, Kristall und Technik 6, 429 (1971).

13. H. J. Bunge, Kristall und Technik 5, 145 (1970).

14. G. I. Taylor, J. Inst. Metals 62, 307 (1938).

15. H. J. Bunge, J. Tobisch and W. Sonntag, J. Appl. Cryst. 4, 303 (1971)

16. J. L. Dillamore, E. Butler and D. Green, Metal Sci.J. 2, 161 (1968).

17. G. Wassermann, $Z$. Metallk. 54, 61 (1963).

18. G. E. R. Schulze, Metallphysik (Akademie-Verlag, Berlin, 1967).

19. H. J. Bunge and J. Tobisch, J. Appl. Cryst. 5, 27 (1972).

20. R. S. Goodman and H. Hu, Trans. Metall. Soc. AIME 242, 88 (1968).

21. T. Leffers and A. Grum-Jensen, Trans. Metall. Soc. AIME 242, 314 (1968).

22. J. L. Dillamore, R. E. Smallman and W. T. Roberts, Phil. Mag. 9, 517 (1964).

23. H. J. Bunge, Kristall und Technik 6, 677 (1972).

24. A. T. English and G. Y. Chin, Acta Met. 13, 1013 (1965).

25. F. Haessner and D. Mayer-Rosa, Z. Metallk. 58, 12 (1967).

26. H. J. Bunge and W. T. Roberts, J. Appl. Cryst. 2, 116 (1969).

\section{Appendix}

The coefficients $C_{l}{ }^{\mu v}$ for the textures of iron sheets cold rolled to different degrees of reduction.

The definition of the coefficients was given in ref. ${ }^{11}$

\begin{tabular}{|c|c|c|c|c|c|c|c|c|c|c|}
\hline 1 & $\mathrm{~m}$ & $\mathbf{n}$ & $0 \%$ & $30 \%$ & $50 \%$ & $70 \%$ & $76 \%$ & $84 \%$ & $86 \%$ & $95 \%$ \\
\hline 4 & 1 & $\begin{array}{l}0 \\
2 \\
4\end{array}$ & $\begin{array}{l}-0.14 \\
-0.42 \\
-0.60\end{array}$ & $\begin{array}{l}-0.40 \\
-0.45 \\
-0.60\end{array}$ & $\begin{array}{l}-0.49 \\
-0.40 \\
-0.47\end{array}$ & $\begin{array}{l}-0.60 \\
-0.55 \\
-1.18\end{array}$ & $\begin{array}{r}-0.76 \\
-0.50 \\
-1.20\end{array}$ & $\begin{array}{l}-0.60 \\
-0.61 \\
-1.64\end{array}$ & $\begin{array}{l}-0.66 \\
-0.64 \\
-1.83\end{array}$ & $\begin{array}{l}-0.45 \\
-0.76 \\
-2.50\end{array}$ \\
\hline 6 & 1 & $\begin{array}{l}0 \\
2 \\
4 \\
6\end{array}$ & $\begin{array}{r}0.10 \\
-0.13 \\
0.26 \\
0.17\end{array}$ & $\begin{array}{r}2.00 \\
-1.90 \\
0.79 \\
0.05\end{array}$ & $\begin{array}{r}2.60 \\
-2.31 \\
0.90 \\
0.08\end{array}$ & $\begin{array}{r}3.27 \\
-2.78 \\
0.79 \\
-0.19\end{array}$ & $\begin{array}{r}3.30 \\
-2.77 \\
0.82 \\
-0.16\end{array}$ & $\begin{array}{r}3.38 \\
-2.84 \\
0.84 \\
-0.47\end{array}$ & $\begin{array}{r}3.41 \\
-3.08 \\
0.89 \\
-0.52\end{array}$ & $\begin{array}{r}3.53 \\
-3.39 \\
1.27 \\
-1.37\end{array}$ \\
\hline 8 & 1 & $\begin{array}{l}0 \\
2 \\
4 \\
6 \\
8\end{array}$ & $\begin{array}{r}-0.06 \\
0.10 \\
-0.08 \\
0.22 \\
0.29\end{array}$ & $\begin{array}{r}0.25 \\
-0.04 \\
0.17 \\
0.27 \\
0.30\end{array}$ & $\begin{array}{r}0.34 \\
-0.12 \\
0.26 \\
0.25 \\
0.26\end{array}$ & $\begin{array}{r}0.46 \\
-0.15 \\
0.97 \\
-0.07 \\
0.67\end{array}$ & $\begin{array}{r}0.54 \\
-0.17 \\
1.04 \\
-0.02 \\
0.72\end{array}$ & $\begin{array}{r}0.42 \\
-0.19 \\
1.40 \\
-0.41 \\
1.17\end{array}$ & $\begin{array}{r}0.54 \\
-0.22 \\
1.48 \\
-0.43 \\
1.30\end{array}$ & $\begin{array}{r}0.48 \\
-0.22 \\
2.01 \\
-0.86 \\
2.21\end{array}$ \\
\hline 10 & 1 & $\begin{array}{r}0 \\
2 \\
4 \\
6 \\
8 \\
10\end{array}$ & $\begin{array}{r}0.07 \\
-0.29 \\
0.09 \\
0.02 \\
-0.07 \\
-0.07\end{array}$ & $\begin{array}{r}-0.34 \\
0.02 \\
0.07 \\
0.17 \\
-0.21 \\
0.06\end{array}$ & $\begin{array}{r}-0.43 \\
0.10 \\
0.01 \\
0.24 \\
-0.28 \\
0.03\end{array}$ & $\begin{array}{r}-0.83 \\
0.31 \\
-0.10 \\
0.47 \\
-0.29 \\
0.12\end{array}$ & $\begin{array}{r}-0.84 \\
0.28 \\
-0.19 \\
0.44 \\
-0.32 \\
0.14\end{array}$ & $\begin{array}{r}-0.80 \\
0.21 \\
-0.17 \\
0.50 \\
-0.23 \\
0.43\end{array}$ & $\begin{array}{r}-0.89 \\
0.33 \\
0.15 \\
0.29 \\
-0.12 \\
0.38\end{array}$ & $\begin{array}{r}-1.00 \\
0.21 \\
-0.03 \\
0.30 \\
0.43 \\
0.78\end{array}$ \\
\hline
\end{tabular}




\begin{tabular}{|c|c|c|c|c|c|c|c|c|c|c|}
\hline 1 & $\mathrm{~m}$ & $\mathbf{n}$ & $0 \%$ & $30 \%$ & $50 \%$ & $70 \%$ & $76 \%$ & $84 \%$ & $86 \%$ & $95 \%$ \\
\hline 12 & $\begin{array}{l}1 \\
2 \\
1 \\
2 \\
1 \\
2 \\
1 \\
2 \\
1 \\
2 \\
1 \\
1 \\
2 \\
1\end{array}$ & $\begin{array}{r}0 \\
2 \\
4 \\
6 \\
8 \\
10 \\
12\end{array}$ & $\begin{array}{r}-0.06 \\
-0.29 \\
-0.00 \\
0.56 \\
-0.05 \\
-0.53 \\
0.05 \\
0.34 \\
-0.04 \\
-0.15 \\
0.01 \\
0.01 \\
-0.13 \\
0.01\end{array}$ & $\begin{array}{r}-0.09 \\
-0.88 \\
-0.02 \\
1.09 \\
-0.03 \\
-0.66 \\
-0.13 \\
0.24 \\
-0.07 \\
-0.06 \\
0.10 \\
0.02 \\
-0.13 \\
-0.02\end{array}$ & $\begin{array}{r}-0.06 \\
-1.39 \\
-0.04 \\
1.69 \\
0.02 \\
-1.05 \\
-0.15 \\
0.40 \\
-0.06 \\
-0.07 \\
0.07 \\
0.04 \\
-0.11 \\
-0.02\end{array}$ & $\begin{array}{r}-0.08 \\
-2.19 \\
0.07 \\
2.50 \\
-0.23 \\
-1.23 \\
-0.11 \\
0.40 \\
-0.30 \\
-0.16 \\
0.14 \\
0.18 \\
-0.35 \\
0.03\end{array}$ & $\begin{array}{r}-0.03 \\
-2.12 \\
0.01 \\
2.50 \\
-0.23 \\
-1.25 \\
-0.15 \\
0.37 \\
-0.32 \\
-0.20 \\
0.15 \\
0.21 \\
-0.40 \\
-0.02\end{array}$ & $\begin{array}{r}-0.19 \\
-2.26 \\
0.08 \\
2.68 \\
-0.50 \\
-1.42 \\
-0.04 \\
0.50 \\
-0.61 \\
-0.36 \\
0.50 \\
0.37 \\
-0.79 \\
-0.03\end{array}$ & $\begin{array}{r}-0.09 \\
-2.41 \\
0.12 \\
2.75 \\
-0.32 \\
-1.42 \\
-0.08 \\
0.56 \\
-0.70 \\
-0.38 \\
0.56 \\
0.36 \\
-0.91 \\
0.02\end{array}$ & $\begin{array}{r}-0.24 \\
-2.64 \\
0.24 \\
3.21 \\
-0.86 \\
-1.41 \\
-0.02 \\
0.82 \\
-1.04 \\
-1.04 \\
1.19 \\
0.95 \\
-2.06 \\
-0.28\end{array}$ \\
\hline 14 & 1 & $\begin{array}{r}0 \\
2 \\
4 \\
6 \\
8 \\
10 \\
12 \\
14\end{array}$ & $\begin{array}{r}0.10 \\
-0.04 \\
0.05 \\
-0.05 \\
0.04 \\
-0.01 \\
0.02 \\
-0.01\end{array}$ & $\begin{array}{r}0.23 \\
-0.16 \\
0.09 \\
-0.08 \\
-0.02 \\
0.01 \\
0.05 \\
-0.01\end{array}$ & $\begin{array}{r}0.28 \\
-0.22 \\
0.16 \\
-0.11 \\
-0.01 \\
0.00 \\
0.05 \\
0.00\end{array}$ & $\begin{array}{r}0.49 \\
-0.48 \\
0.65 \\
-0.56 \\
0.23 \\
-0.14 \\
0.06 \\
-0.07\end{array}$ & $\begin{array}{r}0.47 \\
-0.52 \\
0.65 \\
-0.53 \\
0.28 \\
-0.21 \\
0.07 \\
-0.07\end{array}$ & $\begin{array}{r}0.40 \\
-0.71 \\
0.87 \\
-0.82 \\
0.43 \\
-0.29 \\
0.13 \\
-0.18\end{array}$ & $\begin{array}{r}0.84 \\
-0.93 \\
1.05 \\
-0.85 \\
0.50 \\
-0.35 \\
0.09 \\
-0.17\end{array}$ & $\begin{array}{r}0.39 \\
-0.38 \\
1.08 \\
-1.05 \\
0.55 \\
-0.35 \\
-0.27 \\
-0.59\end{array}$ \\
\hline 16 & $\begin{array}{l}1 \\
2 \\
1 \\
2 \\
1 \\
2 \\
1 \\
2 \\
1 \\
2 \\
1 \\
2 \\
1 \\
2 \\
1 \\
2 \\
1 \\
2\end{array}$ & $\begin{array}{r}4 \\
6 \\
8 \\
8 \\
10 \\
12 \\
14 \\
16\end{array}$ & $\begin{array}{r}-0.15 \\
-0.32 \\
-0.01 \\
0.05 \\
0.01 \\
-0.05 \\
-0.02 \\
-0.06 \\
0.02 \\
-0.00 \\
-0.04 \\
-0.04 \\
0.01 \\
0.05 \\
0.05 \\
0.06 \\
0.06 \\
0.02\end{array}$ & $\begin{array}{r}-0.10 \\
-0.02 \\
-0.01 \\
-0.05 \\
0.03 \\
0.08 \\
-0.00 \\
-0.10 \\
-0.04 \\
0.03 \\
-0.02 \\
-0.10 \\
0.08 \\
0.10 \\
-0.01 \\
-0.07 \\
0.03 \\
-0.04\end{array}$ & $\begin{array}{r}-0.15 \\
0.01 \\
0.01 \\
-0.14 \\
0.05 \\
0.12 \\
-0.03 \\
-0.23 \\
-0.00 \\
0.04 \\
0.01 \\
-0.10 \\
0.01 \\
-0.06 \\
0.02 \\
0.07 \\
0.04 \\
0.01\end{array}$ & $\begin{array}{r}-0.15 \\
0.29 \\
-0.00 \\
-0.38 \\
0.07 \\
0.15 \\
-0.08 \\
-0.31 \\
0.25 \\
0.37 \\
-0.07 \\
-0.24 \\
0.01 \\
-0.12 \\
-0.11 \\
-0.05 \\
0.24 \\
0.11\end{array}$ & $\begin{array}{r}-0.14 \\
0.22 \\
-0.10 \\
-0.46 \\
0.08 \\
0.25 \\
-0.02 \\
-0.22 \\
0.23 \\
0.32 \\
0.03 \\
-0.12 \\
0.05 \\
-0.07 \\
-0.13 \\
-0.07 \\
0.20 \\
0.04\end{array}$ & $\begin{array}{r}0.03 \\
0.44 \\
0.07 \\
-0.46 \\
0.20 \\
0.20 \\
-0.13 \\
-0.30 \\
0.35 \\
0.27 \\
-0.17 \\
-0.23 \\
0.31 \\
0.13 \\
-0.38 \\
-0.26 \\
0.53 \\
0.09\end{array}$ & $\begin{array}{r}-0.00 \\
0.58 \\
-0.07 \\
-0.49 \\
0.16 \\
0.16 \\
-0.07 \\
-0.04 \\
0.34 \\
0.15 \\
-0.14 \\
-0.03 \\
0.38 \\
0.07 \\
-0.40 \\
-0.23 \\
0.57 \\
0.09\end{array}$ & $\begin{array}{r}-0.04 \\
0.68 \\
-0.08 \\
-0.82 \\
0.30 \\
0.01 \\
-0.01 \\
-0.05 \\
0.68 \\
-0.20 \\
-0.33 \\
0.36 \\
0.67 \\
0.14 \\
-1.00 \\
-0.50 \\
1.64 \\
0.27\end{array}$ \\
\hline 18 & $\begin{array}{l}1 \\
2 \\
1 \\
2 \\
1 \\
2 \\
1 \\
2 \\
1 \\
2 \\
1 \\
2 \\
1 \\
2 \\
1 \\
2 \\
1 \\
2 \\
1 \\
2\end{array}$ & $\begin{array}{l}12 \\
14\end{array}$ & $\begin{array}{r}-0.04 \\
-0.04 \\
-0.13 \\
0.10 \\
0.14 \\
-0.06 \\
-0.01 \\
0.01 \\
0.01 \\
-0.02 \\
0.00 \\
0.02 \\
-0.05 \\
-0.03 \\
0.02 \\
0.00 \\
-0.06 \\
0.02 \\
-0.03 \\
-0.01\end{array}$ & $\begin{array}{r}-0.22 \\
-0.22 \\
0.07 \\
0.37 \\
-0.04 \\
-0.25 \\
0.06 \\
0.12 \\
0.02 \\
-0.06 \\
0.00 \\
0.04 \\
0.02 \\
-0.06 \\
0.11 \\
-0.04 \\
-0.00 \\
0.00 \\
0.10 \\
-0.05\end{array}$ & $\begin{array}{r}-0.17 \\
-0.54 \\
0.02 \\
0.74 \\
0.01 \\
-0.48 \\
-0.02 \\
0.35 \\
0.02 \\
-0.09 \\
0.01 \\
0.06 \\
-0.01 \\
-0.03 \\
-0.04 \\
0.05 \\
0.02 \\
-0.03 \\
-0.01 \\
-0.00\end{array}$ & $\begin{array}{r}-0.29 \\
-1.00 \\
0.09 \\
1.36 \\
-0.26 \\
-0.78 \\
0.18 \\
0.38 \\
-0.14 \\
-0.15 \\
0.17 \\
0.12 \\
-0.13 \\
-0.09 \\
0.01 \\
0.06 \\
-0.01 \\
-0.03 \\
0.06 \\
-0.04\end{array}$ & $\begin{array}{r}-0.27 \\
-1.01 \\
0.14 \\
1.38 \\
-0.20 \\
-0.87 \\
0.16 \\
0.44 \\
-0.22 \\
-0.08 \\
0.26 \\
0.08 \\
-0.23 \\
-0.02 \\
0.10 \\
0.07 \\
-0.04 \\
0.01 \\
0.03 \\
0.11\end{array}$ & $\begin{array}{r}-0.18 \\
-1.06 \\
0.44 \\
1.71 \\
-0.41 \\
-1.04 \\
0.32 \\
0.46 \\
-0.33 \\
-0.33 \\
0.43 \\
0.31 \\
-0.34 \\
-0.20 \\
0.27 \\
0.07 \\
-0.11 \\
-0.04 \\
0.12 \\
-0.03\end{array}$ & $\begin{array}{r}-0.35 \\
-1.24 \\
-0.02 \\
1.62 \\
-0.51 \\
-0.88 \\
0.28 \\
0.34 \\
-0.22 \\
-0.18 \\
0.37 \\
0.15 \\
-0.34 \\
-0.09 \\
0.25 \\
0.04 \\
-0.04 \\
-0.06 \\
0.12 \\
-0.02\end{array}$ & $\begin{array}{r}-0.52 \\
-1.35 \\
0.51 \\
1.79 \\
-0.94 \\
-0.83 \\
0.66 \\
0.29 \\
-0.60 \\
-0.42 \\
0.56 \\
0.69 \\
-0.34 \\
-0.39 \\
0.10 \\
0.40 \\
0.13 \\
-0.44 \\
0.20 \\
0.11\end{array}$ \\
\hline
\end{tabular}




\begin{tabular}{|c|c|c|c|c|c|c|c|c|c|c|}
\hline 1 & $\mathrm{~m}$ & $\mathbf{n}$ & $0 \%$ & $30 \%$ & $50 \%$ & $70 \%$ & $76 \%$ & $84 \%$ & $86 \%$ & $95 \%$ \\
\hline \multirow[t]{22}{*}{20} & 1 & 0 & 0.01 & -0.06 & 0.00 & -0.05 & 0.00 & -0.07 & -0.07 & 0.19 \\
\hline & 2 & & 0.16 & 0.10 & 0.17 & 0.17 & 0.24 & -0.09 & -0.01 & 0.37 \\
\hline & 1 & 2 & -0.06 & -0.01 & -0.07 & -0.16 & -0.04 & 0.01 & -0.07 & -0.31 \\
\hline & 2 & & 0.16 & 0.08 & 0.10 & 0.26 & 0.24 & 0.46 & 0.54 & -0.00 \\
\hline & 1 & 4 & 0.00 & -0.03 & 0.01 & 0.00 & 0.05 & 0.03 & 0.05 & 0.14 \\
\hline & 2 & & -0.06 & -0.03 & -0.10 & -0.38 & -0.22 & -0.29 & -0.53 & -0.12 \\
\hline & 1 & 6 & 0.00 & -0.00 & -0.07 & -0.02 & -0.00 & 0.02 & -0.05 & -0.08 \\
\hline & 2 & & 0.06 & -0.02 & -0.01 & 0.31 & 0.26 & 0.64 & 0.44 & 0.37 \\
\hline & 1 & 8 & -0.02 & -0.03 & 0.00 & -0.01 & -0.09 & -0.10 & -0.02 & -0.17 \\
\hline & 2 & & 0.03 & 0.03 & -0.07 & -0.19 & -0.28 & -0.29 & -0.23 & 0.00 \\
\hline & 1 & 10 & 0.03 & -0.01 & -0.01 & 0.04 & 0.02 & 0.03 & -0.03 & -0.11 \\
\hline & 2 & & 0.01 & 0.04 & 0.01 & 0.13 & 0.08 & 0.17 & 0.10 & -0.22 \\
\hline & 1 & 12 & -0.00 & 0.01 & -0.01 & 0.03 & -0.05 & -0.13 & -0.09 & -0.16 \\
\hline & 2 & & -0.01 & 0.02 & -0.02 & -0.06 & -0.07 & -0.14 & 0.01 & 0.09 \\
\hline & 1 & 14 & 0.03 & -0.03 & -0.01 & 0.01 & 0.04 & 0.12 & 0.07 & 0.15 \\
\hline & 2 & & 0.01 & -0.08 & 0.01 & 0.06 & 0.04 & 0.06 & 0.04 & -0.04 \\
\hline & 1 & 16 & -0.02 & 0.06 & -0.03 & -0.05 & -0.00 & -0.16 & -0.18 & -0.30 \\
\hline & 2 & & 0.05 & -0.03 & -0.01 & -0.02 & -0.08 & -0.04 & -0.00 & -0.07 \\
\hline & 1 & 18 & -0.02 & 0.07 & -0.01 & 0.06 & 0.07 & 0.19 & 0.26 & 0.64 \\
\hline & 2 & & 0.01 & -0.08 & -0.01 & 0.05 & 0.05 & -0.02 & -0.01 & -0.01 \\
\hline & 1 & 20 & -0.04 & -0.08 & -0.04 & -0.11 & -0.17 & -0.26 & -0.31 & -1.06 \\
\hline & 2 & & 0.00 & 0.01 & -0.02 & -0.02 & -0.11 & 0.09 & 0.02 & 0.05 \\
\hline \multirow[t]{24}{*}{22} & 1 & 0 & -0.07 & -0.04 & -0.16 & -0.26 & -0.21 & -0.21 & 0.12 & -0.95 \\
\hline & 2 & & 0.02 & 0.32 & 0.27 & -0.00 & 0.17 & -0.00 & 0.90 & -0.61 \\
\hline & 1 & 2 & 0.12 & 0.01 & -0.06 & -0.09 & 0.29 & 0.39 & -0.00 & 0.72 \\
\hline & 2 & & 0.37 & -0.10 & -0.26 & -0.30 & 0.47 & 0.67 & -0.09 & 0.66 \\
\hline & 1 & 4 & -0.02 & 0.01 & -0.06 & -0.16 & -0.01 & 0.01 & -0.09 & -0.45 \\
\hline & 2 & & -0.17 & -0.00 & -0.17 & -0.27 & 0.11 & -0.18 & -0.39 & -0.43 \\
\hline & 1 & 6 & 0.04 & 0.07 & -0.09 & 0.05 & 0.09 & -0.02 & 0.24 & 0.71 \\
\hline & 2 & & 0.24 & 0.21 & -0.22 & 0.22 & 0.21 & 0.11 & 0.63 & 1.42 \\
\hline & 1 & 8 & -0.02 & -0.12 & 0.08 & -0.10 & 0.00 & 0.17 & -0.24 & -0.12 \\
\hline & 2 & & -0.09 & -0.33 & 0.25 & -0.30 & -0.07 & 0.04 & -0.65 & -0.59 \\
\hline & 1 & 10 & 0.04 & 0.10 & 0.11 & -0.06 & -0.20 & -0.23 & 0.13 & -0.10 \\
\hline & 2 & & 0.06 & 0.17 & 0.21 & 0.13 & -0.27 & 0.00 & 0.51 & 0.20 \\
\hline & 1 & 12 & 0.02 & 0.04 & -0.08 & 0.06 & 0.21 & 0.24 & -0.19 & 0.25 \\
\hline & 2 & & 0.03 & 0.15 & -0.18 & 0.04 & 0.41 & 0.17 & -0.47 & 0.24 \\
\hline & 1 & 14 & -0.00 & -0.11 & -0.00 & -0.08 & -0.14 & -0.24 & 0.10 & -0.02 \\
\hline & 2 & & -0.02 & -0.30 & 0.01 & -0.06 & -0.10 & -0.12 & 0.36 & 0.13 \\
\hline & 1 & 16 & -0.03 & 0.01 & -0.06 & 0.27 & 0.12 & 0.19 & 0.16 & 0.45 \\
\hline & 2 & & -0.09 & -0.02 & -0.17 & 0.61 & 0.05 & 0.06 & 0.00 & 0.77 \\
\hline & 1 & 18 & -0.03 & -0.10 & 0.02 & -0.10 & 0.01 & -0.05 & -0.05 & -0.20 \\
\hline & 2 & & 0.06 & -0.10 & 0.08 & -0.11 & 0.15 & 0.13 & 0.08 & -0.60 \\
\hline & 1 & 20 & 0.01 & -0.01 & 0.09 & 0.02 & -0.05 & 0.07 & 0.17 & 0.37 \\
\hline & 2 & & 0.04 & -0.03 & 0.18 & -0.08 & -0.10 & 0.02 & 0.29 & 1.10 \\
\hline & 1 & 22 & 0.03 & -0.01 & -0.08 & 0.05 & -0.00 & -0.02 & -0.02 & -0.82 \\
\hline & 2 & & 0.04 & -0.04 & -0.20 & 0.15 & -0.09 & 0.16 & 0.13 & -1.62 \\
\hline
\end{tabular}

